\title{
The Sociolinguistic Perspective of Hedging in English
}

\section{Kristine Harutyunyan, Anna Sargsyan}

Yerevan State University

\begin{abstract}
Hedging refers to linguistic strategies which qualify categorical commitment, expressing possibility and probability rather than certainty. Hedges express tentativeness and possibility in communication, so their appropriate use in different discourses is vital. The aim of the present paper is to describe and analyze the social factors and social parameters that influence and determine the use of hedging in English speech; particularly we focus on gender, occupation, topic and setting while examining each type of speech. The famous TED talks (usually short, influential and powerful) serve as a primary source of investigation.
\end{abstract}

Key words: sociolinguistic perspective, social interaction, hedging, social factors, TED talks.

\section{Introduction}

Sociolinguistics as a discipline studies a wide variety of dialects to analyze different social variables influencing the speaker's language. It often shows the humorous realities of human speech and how a dialect of a given language can describe the speaker's age, gender, social class or the level of education.

The basic components in sociolinguistic explanations of why we speak differently in different social contexts are the social factors. They are very important in describing and analyzing all kinds of information. In any situation linguistic choices generally indicate people's awareness of the influence of one or more social factors (Holmes 2013).

Language variation allows to locate speakers in a multi-dimensional society. Age is one of the dimensions on which we construct identities for 
ourselves and others. Gender also plays an important role in language variation as we have linguistic differences between male and female speech (Lakoff 1975).

Hedges are communicative strategies for reducing the force of statements, to show doubt and indicate that information is presented as opinion rather than accredited fact. Hedges may be understood as positive or negative politeness in which the writer or speaker tries to appear humble rather than arrogant or allknowing. It also guarantees a certain level of acceptability in a community, so one could consider hedges as ways of being more precise in reporting results. Hedging may present the true state of the writers' or speakers' unerstanding and may be used to negotiate an accurate representation of the state of the knowledge under discussion. By hedging, authors or speakers tone down their statements in order to reduce the risk of opposition.

There is much dispute about the linguistic difference between men and women, about the language they use. Hedging, being a kind of politeness marker, plays an important role in showing the differences of its usage from a sociolinguistic perspective, particularly focusing on such social and contextual parameters as gender, class, age, ethnicity, setting, etc.

Thus, our intention has been to carry out quantitative and qualitative analyses from a sociolinguistic perspective of twenty-minute speeches of ten people (five men and five women) to provide a detailed interpretation of hedges used in male and female speeches.

\section{A Case Study of Hedging from a Sociolinguistic Perspective}

Sociolinguistics studies language in general and particular linguistic items in relation to the society which uses it. In any situation linguistic choices generally reflect the influence of the setting or social context of the interaction. This is one of the basic components in sociolinguistic explanations of why we speak differently in different social contexts (Hickey 2007). The context in language use is very important, for linguistic and social behavior not only has to be appropriate to the individual and his socio-economic background, but it also needs to be suitable for particular occasions and situations. 
Investigating the social context of TED talks, we have observed that almost in all the speeches the setting is primarily informal, friendly and inspiring, which presupposes free usage of various language means by the speakers. And hedging devices as common linguistic means of communicative strategies are abundantly utilized by the speakers in talks for different purposes. Hedges are widely used in conversation and in social interaction since they tone down and reduce the force of the statements and indicate that the information is presented as opinion rather than accredited fact.

Thus we can say that the benevolent setting of TED talks contribute to the unrestrained code choice. As an exemplification we can mention the usage of vulgar words by one of the speakers in his speech. Moreover, if we take into account the fact that the audiences are people of various interests and occupation, and that they are not indispensably representatives of science, technology, psychology or culture, then the usage of diverse linguistic means, in our case the utilization of hedging, is completely justified.

Context in language use is very important, for linguistic and social behavior not only has to be appropriate to the individual and his socio-economic background, but it also needs to be suitable for particular occasions and situations. In other words, language varies not only according to the social characteristics of the speaker but also according to the social context in which he finds himself.

For a more in-depth analysis of the material we have considered the occupations of the speakers which also deals with the themes touched upon by them. The largest amount of hedges is used by Amy Cuddy (132), who is a social psychologist, a professor and a researcher. She delivers her speech on body language and how nonverbal behavior affects people's perceptions. The next, in terms of the amount of hedges used in the speech, is Brené Brown (79), a vulnerability researcher who speaks about a personal quest to know herself and to understand humanity. Then comes Susan Cain (51), she is a former corporate lawyer and negotiations consultant who argues that introverts bring extraordinary talents and abilities to the world. The health psychologist Kelly McGonial (42) states that stress is a positive thing. The last one is the famous 
model Cameron Russell (34) speaking about beauty and trying to prove that looks are not everything. This study of women's speech shows that the number of hedges used in female speech varies from speaker to speaker, confirming the fact that the big amount of hedging used in female speech is not only conditioned by the gender of the speaker but also by the speaker herself.

Considering men's speech we have noticed that the number of hedges used by men is not much as compared with that of the women. This may promote a preconceived idea that women use more hedges than men because of their gender differences, if not for other social factors and social parameters that should be taken into consideration.

For a more comprehensive and thorough analysis let us take into consideration the occupation of each of the speakers and reveal the subject matter of their speech. Among men Ken Robinson used the largest amount of hedges (48). He is a creativity expert who challenges the school system to cultivate creativity and acknowledge multiple types of intelligence. Next is Pranav Mistry (44), a MIT graduate student who invented SixthSense wearable device that enables new interactions between the real world and the world of data. The life coach and expert in leadership psychology Tony Robbins (43) discusses in his speech the "invisible forces" that motivate our actions in order to know why we do what we do. The leadership expert Simon Sinek (21) presents a simple, but powerful model for inspirational leadership-starting with a golden circle. And the last one is the career analyst Dan Pink (20) who examines the puzzle of motivation with a fact that social scientists know. This study, first of all, has revealed that women use more hedging devices and politeness markers than men do during their speech. Women mentioned above used about 338 hedging devices of different kinds, while men used only 176 hedges. This is a considerable quantitative difference between the two genders, which might give a preconceived idea that gender presupposes some extent of certainty or lack of certainty. 


\section{Hedging and Its Functions in Speech}

The notion that gender presupposes some extent of certainty or lack of certainty is not an absolute one. Moreover, such an explanation is too narrow and restrained because the possible different communicative functions of hedges have not been taken into consideration. By functions we namely mean the inclusion of others into speech or arousing interest in the topic. In other words, hedges can function as conversational facilitation strategies to keep the conversation flowing, and when considering cross-gender issues it is of paramount importance to take into account the different functions and purposes of the employed strategies, as well as the various social factors and social parameters that can influence the code choice of the speaker (Fishman 1983).

In examining the usage of hedging by two genders the investigation of the mere quantity used by two genders is not sufficient. It is also necessary to take into consideration the taxonomy of hedging devices, i.e. the main types of hedging used during the speech (Salager-Meyer 1997). It is of paramount importance to get a more comprehensive sociolinguistic picture of the speech material under consideration and this will be done by calculating which kinds of hedges are mostly used and for what purposes.

The most frequently used type of hedging by two genders is the introductory phrases. These hedges are mainly used during the speech as false starts, as markers of hesitation and subjectivity. The next commonly used hedging device differs across gender, in men's speech it is the approximators of degree, quantity, frequency and time, in women's speech it is the adjectival, adverbial and nominal modal phrases. As for the approximators, they are used either because of the speaker's lack of precise information or as strategies of being more accurate in representation. The adjectival, adverbial and nominal modal phrases mainly contain shades of possibility, probability and hesitancy. Yet, we may claim that there are not many quantitative differences between these two types of hedges in men's and women's speech. Such is the case with the modal lexical verbs as well, which express doubt and evaluation rather than mere description. 
And the last three hedges, which have low frequency of usage in male and female speeches - are if-clauses, modal auxiliary verbs and compound hedges. As we have observed in the examples, if-clauses render hypothetical meaning which is deemed possible if certain conditions are met. As far as the modal auxiliary verbs are concerned, they often convey possibility and probability of the action. And the hedging with the least frequency is compound hedges, which also expresses probability but with the help of two hedging items.

Another social factor that is necessary to consider in the process of analyzing the usage of hedging by two genders is the topic. Sociolinguistic studies show that people may select a particular variety, code or language means to discuss a particular topic. That is to say, they use the language which is associated with that particular domain.

Thus, we can also consider the themes and topics discussed in the ten TED Talks to find out whether they play any role in the number of hedges used by the two genders. The main themes and subjects discussed by women are psychology, body language, stress, beauty and vulnerability. If we compare the number of hedges used by Amy Cuddy (132), Kelly McGonial (42) and Susan Cain (51), taking into consideration that all of them dealt with psychological issues, we may deduce that there is much difference in the number of the hedging devices found in the speeches they delivered. As compared to the other two talks which are related to beauty and vulnerability, Cameron Russels uses 34 hedges and Brené Brown uses 80 respectively.

Concluding the study of the hedges used with reference to the topic discussed by women, we can note that talks connected with psychology and different psychological issues include more hedges than others not connected with the mentioned topics. Hence, in case of women's talks, the topic plays not a primary, but an important role in code choice, and in this particular case in the number of hedges.

As for the topics touched upon by men, they include creativity, business, leadership psychology and technology. Simon Sinek’s (21), Tony Robins' (43) and Dan Pink's (20) talks are connected with business and leadership. As we see the number of hedges used by them does not much differ, but compared to the 
other two male speeches, which refer to creativity and technology, the number of hedges does not prevail (Ken Robinson 48 and Pranav Mistry 44). Thus, the topic of the talks is of relevant importance in conditioning the number of hedging devices used by men.

Another reference point to consider frequency of usage of hedges might be a cross-gender analysis, connected with one and the same topic. For example, Amy Cuddy's (132), Susan Cain's (51) and Tony Robins' (43) talks are related to psychology, but the number of hedging devices differs considerably, which shows that although the topic and the theme of the talks play some role with reference to the number of hedges used within the talks by speakers of the same gender, on a broader scale - considering one and the same topic in a male female continuum, the difference is quite vivid in favour of more hedges used by women.

\section{Conclusion}

Considering all the possible social factors and social parameters that could influence the usage of hedging by two genders in speech, we have come to the conclusion that women's abundant utilization of hedging devices is not necessarily conditioned by their inferiority, powerlessness and deficiency, but by the fact that they are better and skilled communicators. Studying gender issues we should focus our attention on all the possible social factors and social parameters, and we should not ignore the role of context and blindly overemphasize the linguistic differences between men and women. Hedging does not only refer to hesitation, doubt, insecurity and lack of confidence; it is also a conversational and politeness strategy which carries out interactional and facilitative functions. Hedging enables us to maintain better interpersonal relationship and to keep the conversation flowing.

\section{References:}

1. Fishman, J.A. (1972) The Sociology of Language: An Interdisciplinary Social Science Approach to Language in Society. Rowley, MA: Newbury House. 
2. Hickey, R. (2007) Language and Society. Cambridge: CUP.

3. Holmes, J. (2013) An Introduction to Sociolinguistics. New York, Routledge, Taylor and Francis group.

4. Lakoff, R. (1975) Language and Woman's Place. New York: Harper \& Row.

5. Salager-Meyer, F. (1997) I Think that Perhaps You Should: A Study of Hedges in Written Scientific Discourse. // Functional approaches to written text: Classroom applications. United States Information Agency.

\section{Sources of Data:}

1. Cain, Susan, The power of introverts. Available at: https://www.ted. com/talks/susan_cain_the_power_of_introverts [Accessed March, 2019]

2. Cuddy, Amy, Your body language shapes who you are. Available at: <https://www.ted.com/talks/amy_cuddy_your_body_language_shapes_wh o_you_are $>$ [Accessed January, 2019]

3. Brown, Brené, The power of vulnerability. Available at: https://www.ted. com/talks/brene_brown_on_vulnerability [Accessed December, 2018]

4. McGonigal, Kelly, How to make stress your friend. Available at: https://www.ted.com/talks/kelly_mcgonigal_how_to_make_stress_your_fri en [Accessed January, 2019]

5. Mistry, Pranav, The thrilling potential of SixthSense technology. Available at: https://www.ted.com/talks/pranav_mistry_the_thrilling_potential_of_ sixthsense_technology [Accessed March, 2019]

6. Pink, Dan, The puzzle of motivation. Available at: https:/www.ted.com/ talks/dan_pink_on_motivation [Accessed December, 2018]

7. Robbins, Tony, Why we do what we do. Available at: https://www.ted. com/talks/tony_robbins_asks_why_we_do_what_we_do [Accessed February, 2019]

8. Robinson, Ken, Do schools kill creativity. Available at: https://www.ted. com/talks/ken_robinson_says_schools_kill_creativity [Accessed March, 2019] 
9. Russell, Cameron, Looks aren't everything. Believe me, I'm a model. Available at: https://www.ted.com/talks/cameron_russell_looks_aren_t_ everything_believe_me_i_m_a_model [Accessed January, 2019]

10. Sinek, Simon, How great leaders inspire action. Available at: https://www.ted.com/talks/simon_sinek_how_great_leaders_inspire_action [Accessed February, 2019]

11. TED Talks (Available at: <https://www.ted.com/> [Accessed January 2019].

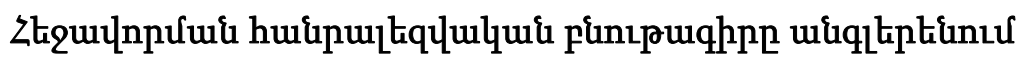

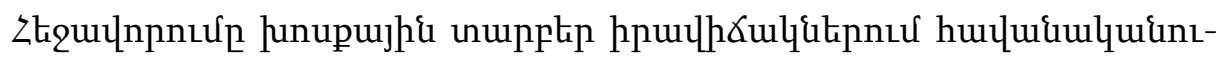

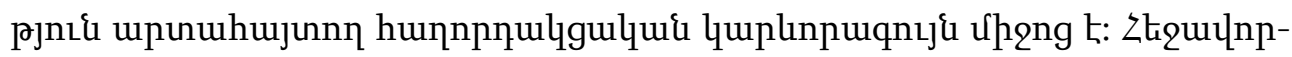

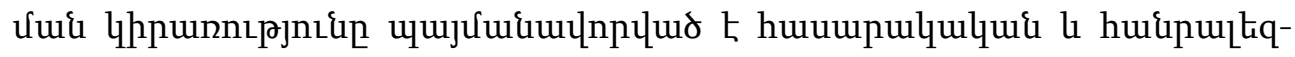

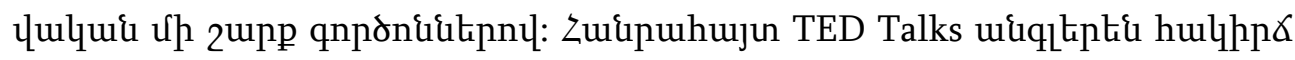

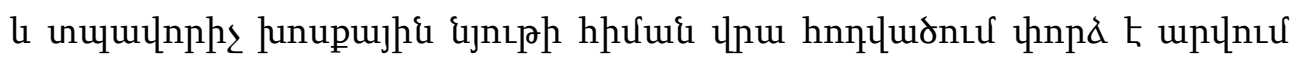

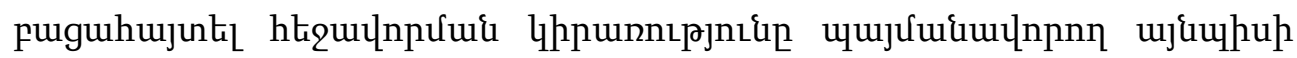

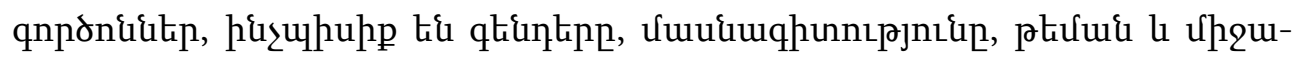
uujnp:

Received by the Editorial Board 25.01.2019

Recommended for publication by the reviewers 05.03.2019

Accepted for print 22.04.2019 